ENTREPRENEURSHIP AND SUSTAINABILITY ISSUES

ISSN 2345-0282 (online) http://jssidoi.org/jesi/ 2019 Volume 7 Number 1 (September)

http://doi.org/10.9770/jesi.2019.7.1(27)

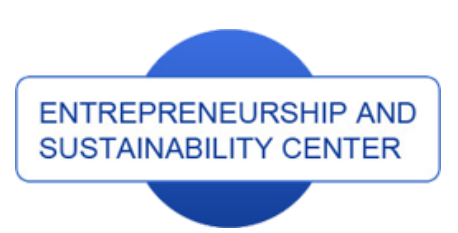

Publisher

http://jssidoi.org/esc/home

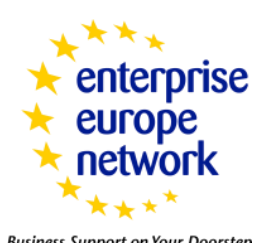

Business Support on Your Doorstep

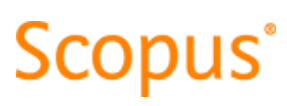

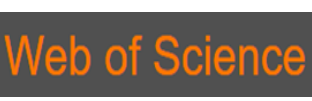

Clarivate
Analytics

\title{
RECOGNITION AND DESCRIPTION OF SYNERGY CONDITIONS IN TEAM WORK IN VIEW OF THE GROUNDED THEORY*
}

\author{
Monika Jasińska \\ Siedlce University of Natural Sciences and Humanities, Faculty of Economic and Law Sciences, \\ Konarskiego Street 2; 08-110 Siedlce, Poland \\ E-mail: monika.jasinska@uph.edu.pl
}

Received 15 February 2019; accepted 2 July 2019; published 30 September 2019

\begin{abstract}
Developing an organisation of the future requires growing potential that will create the foundations for entrepreneurship, innovative activities and sustainable development. Every unit in the organisation's structure is to be a part of this but only team work gives the opportunity to engage the multi-directional potentials in the process. The enhanced cooperation enables any team to achieve exceptional results and the synergy effect. In this context, the value for the development of an organisation is the ability to recognise this phenomenon and indicate the circumstances of its occurrence. In the article, the grounded theory strategy applied in the research, is presented as a method enabling recognition and description of synergy conditions in a team. And based on the methodology, the author aims at explaining the factors deciding on the quality of team work. Given, however, the multidimensional nature of the research on synergy, the main objective of the article is to outline the developed research procedure first stage's endeavours and to discuss the qualitative findings. The employed approach allow keeping apt sequence of delivering empirical evidences proving that synergy is a function of state. The applied concept of grounded theory enabled the researcher to see the key definitions and to indicate variables that would explain the conditions influencing the effectiveness of teams functioning. The ability to present the first part of the findings is, in fact, an opportunity to fortify the voiced arguments that the creative approach, entrepreneurial activity, and social capital are vital to establish the synergy effect in team work. Furthermore, the findings clearly support the concept that synergy is a feature of a team that emerges at specific time, when the team reaches a particular level of relation quality. On top of that, the acquired findings also present that team proficiency and potential growth are, at all times, strengthened by the ability to perceive and implement the synergy effect.
\end{abstract}

Keywords: synergy; grounded theory; team work; quality of relations; entrepreneurship; development

Reference to this paper should be made as follows: Jasińska, M. 2019. Recognition and description of synergy conditions in team work in view of the grounded theory, Entrepreneurship and Sustainability Issues 7(1): 375-397. http://doi.org/10.9770/jesi.2019.7.1(27)

JEL Classifications: L20, L26, O15, M54

\footnotetext{
* The paper has been prepared on the basis of a fundamental research project - Synergy and Social Capital of Modern Organisations. The project was financed by the National Science Centre with funds allocated on the basis of decision-DCE 2011/01/BHS4/04810.
} 


\section{ENTREPRENEURSHIP AND SUSTAINABILITY ISSUES}

ISSN 2345-0282 (online) http://jssidoi.org/jesi/

2019 Volume 7 Number 1 (September)

http://doi.org/10.9770/jesi.2019.7.1(27)

Additional disciplines: sociology, psychology.

\section{Introduction}

The development of modern organisations is a complex process that requires the application of principles of system thinking and undertaking multidimensional activities. Every element of the system, contributes to building cohesion and balance, but it can also be a factor disturbing and destroying the functioning of the organisation as a whole (Sange P., 2014; Senge P., Kleiner A., Roberts C., Ross R., Roth G., Smith B., 1999). The challenge for modern organisations, especially those that show a higher level of development, is proper shaping and utilisation of social potential (Putnam R.D., 2004; Coleman J.C., 1988). Such entities are usually considered to be learning, intelligent or innovative. Therefore only organisations that have the ability to see and use human engagement and creativity will increase their capabilities. The continuously growing ability to create new quality and expected results is the strength of an organisation (Zeeman A., 2017). Thus with the ability to learn at all levels, organisations create an opportunity to be successful in the future (Senge P.M., 2010).

Pointing to people and their potential as a positive energy for strengthening development, it is necessary to emphasise not only their individual contribution. Of particular importance in this way is the sense of progress and creativity potential supported by a team (Amabile T.M., 1988; Amabile T.M., Kramer S.J., 2011; Giedraitis A., Stašys R., Skirpstaite R. 2017). Team work and the value from building high quality social relations are also important. Thanks to the mutual reinforcement of these factors and targeted interactions, conditions can be worked out that, on the basis of teamwork, can create an opportunity for the synergy (Jasińska M., 2015). It is a phenomenon, a new feature, a specific value of a team, which facilitates development and maintains this situation at a sufficiently high level for a sufficiently long time.

\section{Synergy - an enhancement of an organisation's growth}

Organisations operating in a knowledge-based economy, striving to achieve set goals, should develop their own procedures, which will determine their effectiveness. In creating new development models, it is worth taking into account the multidimensional perspective of the organisation's functioning and the system thinking that supports this area. It allows us to see mutual relations, causes and effects of interactions (Senge P.M., 2010; Zeeman A., 2017). A holistic approach to an organisation as a living system will increase its flexibility in determining and accepting changes, especially those of an innovative nature.

The value in today's organisations is the ability to create patterns of thinking, which are triggered by collective aspirations (Zeeman A., 2017). With an established consent and openness to learning together, it is easier to achieve and increase the efficiency and competitiveness. In the dynamically changing conditions, organisational improvement should take into account the development of employee interaction, not only between themselves, but also with the organisation. Building common values, strengthened by openness of attitudes towards mutual learning, will ensure better understanding and use of knowledge management (Albors-Garrigos J., RamosCarrasco J.C., Peiro-Signes A., 2016).

With the idea of creating a learning organisation, one mustn't forget about its relationship with the external environment. In this respect, the organisational culture can support this system, since it creates the basis for the generation, flow and accumulation of knowledge. The organisation's culture regulates these interactions. It significantly affects the quality, openness and development of interaction. Hence, it creates conditions for acquiring and sharing human capital. In this respect, an organisation achieves a continuous potential development. 
By expansion of knowledge, culture and the external environment positively influence innovations in organisations (Chang S.C., Lee M.S., 2008; Atkočiūnienè, Girnienè, 2015).

There is, however, one more aspect significant for building sustainable development - synergy that creates, strengthens and accelerates the process of organisational improvement. It also gives the meaning to the existence of any organisation. Synergy plays a significant creative role in the development of many complex systems. It was recognised as a valuable source of evolutionary novelty. Many point to the real and measurable benefits associated with various forms of synergistic phenomena (Corning P.A., 1995). In the context of learning organisations, synergy achieved through team work is important to their development (Lawford G.R., 2003; Curşeu P.L., Meslec N., Pluut H., Lucas G.J.M., 2015). Due to the fact that it is becoming an increasingly desirable and expected phenomenon in an organisation, this value was taken into account in the elaborated organisational development model (Figure 1). Moreover, substantial part of research, which is described further in the article, focused on identification of the synergy conditions in teams.

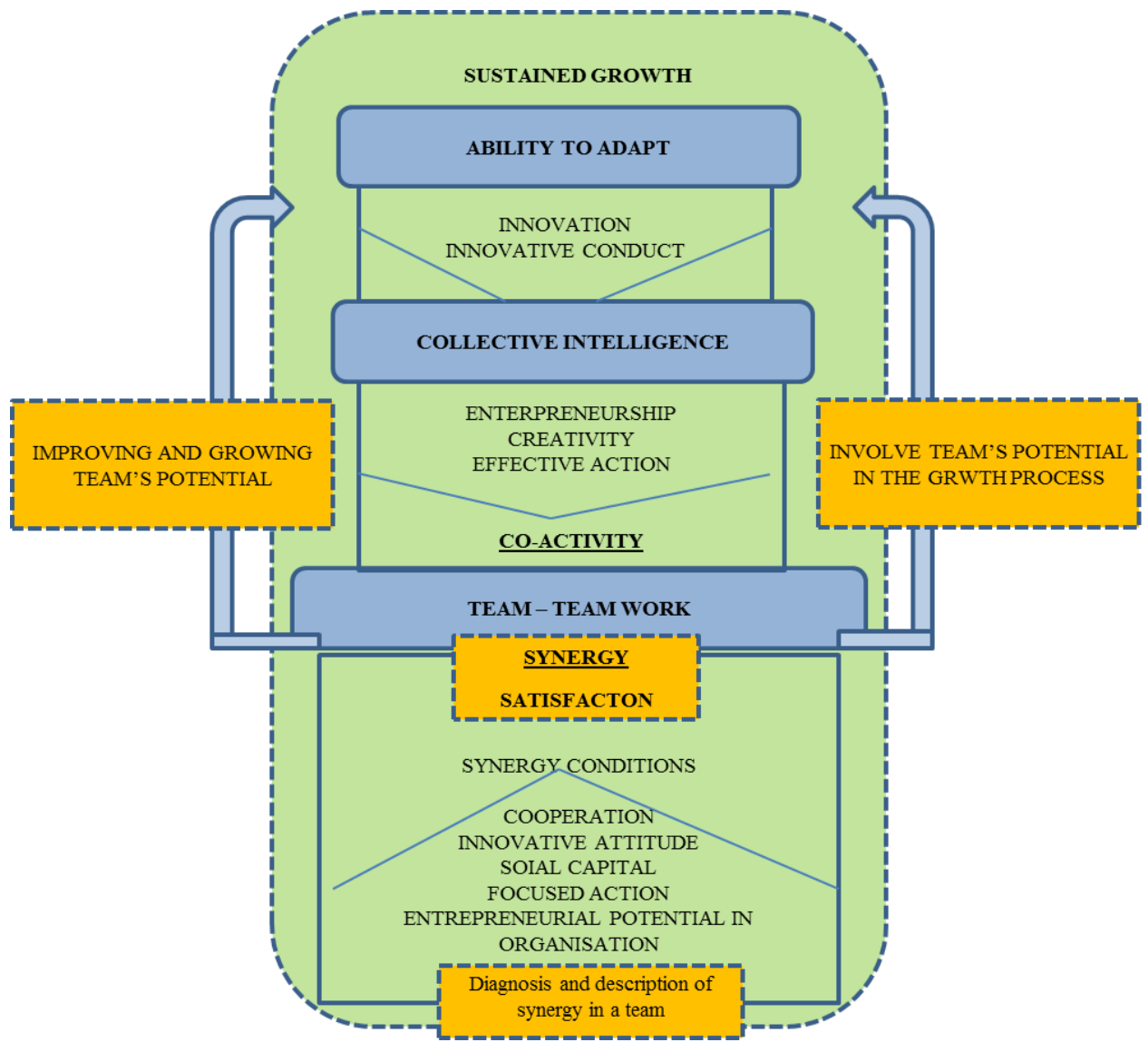

Fig.1 Conditions inducing sustainable development of organisation. Source: own study.

In addition to creating knowledge and learning process, the development model of contemporary organisations, should take into account the direction of self-organisation and self-management in teams. This is crucial due to the benefit of balancing and maximising the potential of the organisation. And the synergy has its fair share in this aspect (Logan L.R, 1995). It creates a qualitative dimension of joint work, generates an additional, outstanding effect (Jasińska M., 2015). The emerging new ownership of a team, based on a joint vision of the future, often 
ENTREPRENEURSHIP AND SUSTAINABILITY ISSUES

ISSN 2345-0282 (online) http://jssidoi.org/jesi/ 2019 Volume 7 Number 1 (September) http://doi.org/10.9770/jesi.2019.7.1(27)

brings the desire to achieve more together. In other words, it is the members of synergistic teams that are more productive and have greater cognitive gain. (Curşeu P.L., Mescel N., Pluut H., Lucas G.J.M., 2015; Černevičiūtė, J., Strazdas R., 2018; Slávik, Š., Hagarová, R., Ljudvigová, I., Zagoršek, B. 2019). Such teams are able to generate ideas that stimulate their actions and initiate entrepreneurial activity. With the idea and the positive interaction in a team, an innovation appears (Rabey G., 2003) and this is the foundation enabling the intelligence of team work (Jasińska M., 2015).

Naturally, no synergy teams could work, if it was not for appropriate support and competence of the management team. Therefore, creating cooperation zones that will facilitate the development of individual competences is of key importance to them. So the ability to use the obtained effects is crucial from the point of view of social processes and managerial work. In this situation, awareness of progress and sense of reason turns out to be a strong reinforcement for further action (Amabile T.M., Kramer, S.J., 2011). Any development of synergistic teams needs a leadership and apt organisational culture that would enhance their actions. Executives are expected to set a good example, encourage innovation and support the process of mutual learning. In this context, managers are required to improve not only team potential, but also their own competences (Chang S.C., Lee, M.S., 2007).

The team is an example of a complex system - (micro) system. Its efficiency builds on harmony laws. Proper selection of people, cooperation as a joint social relation (bonds) as well as organisation of work, give the opportunity to organise mutual actions. This creates the directed energy of a team. The strength that is consciously reinforced, maintained and optimally used, that triggers increased activity, mutual motivation and effective actions of individuals (Rabey G., 2003). In a learning organisation, the team work satisfaction appears along with the well-used activity. The satisfaction is important for the quality of the organisation's results. It affects commitment, motivation and performance (Chang SC, Lee MS, 2007; Erdem M., İlğan A., Uçar H.I., 2014). Satisfaction from work is essential for both employees and the organisation.

\section{The general project of studying the phenomenon of synergy}

The research plan to recognise and describe the synergy conditions in team work composes of three essential stages, which focus on the preparation and implementation of qualitative research and activities in the field of survey and statistical analysis, carried out as part of quantitative research. The graphical sequence of actions is shown in Fig. 2.

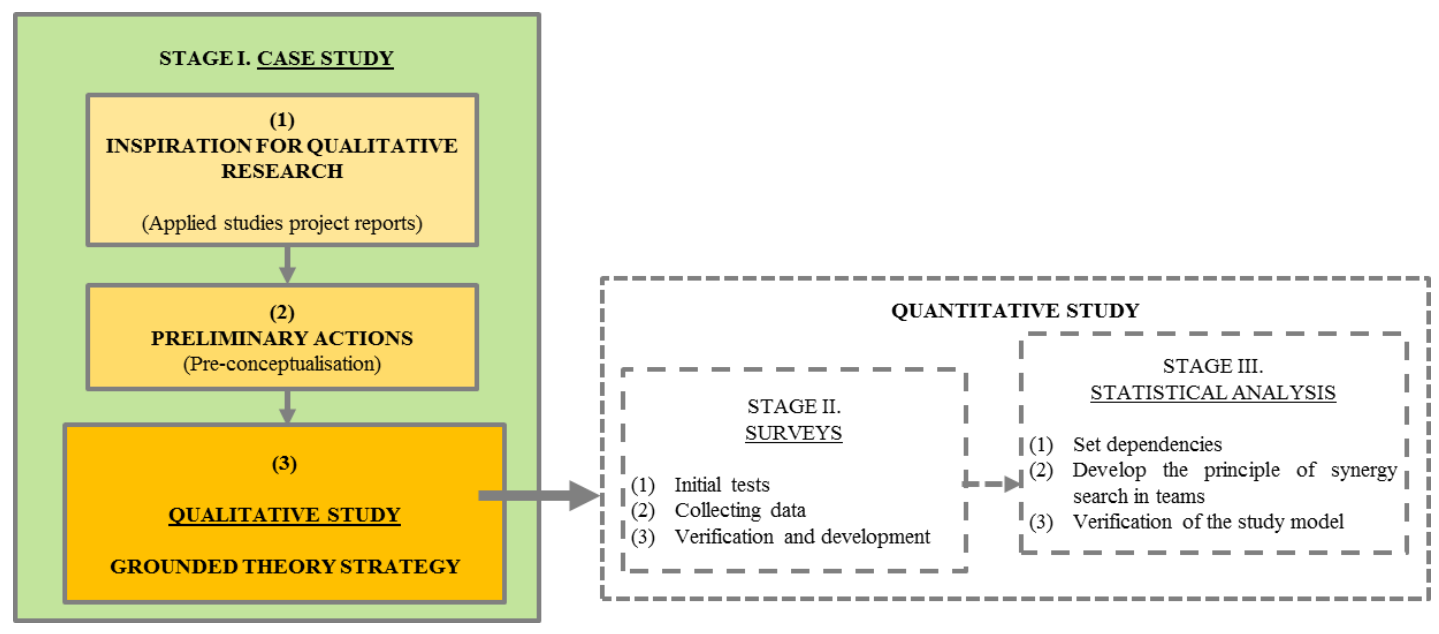

Fig. 2. The research plan to identify and describe the phenomenon of synergy in a team Source: own study. 


\section{ENTREPRENEURSHIP AND SUSTAINABILITY ISSUES}

ISSN 2345-0282 (online) http://jssidoi.org/jesi/ 2019 Volume 7 Number 1 (September) http://doi.org/10.9770/jesi.2019.7.1(27)

The first stage, using the case study method and the implementation of qualitative research, starts in the data acquisition process. In this respect, the first stage of the study was carried out mainly on the basis of the grounded theory method (Konecki K.T., 2011; Charmaz K., 2014). At this step, I defined the scope of terminology describing synergy and gathered data on team performance. The second and third stages of the research process are related to the implementation of quantitative research. The survey studies included diverse, large groups and companies. In total, I ended up with 1394 correctly completed surveys. This material was the starting point to indicate both detailed and general assumptions of synergy in a team.

Subsequently, a statistical analysis of the research results was carried out (descriptive statistics, factor analysis, Pearson's correlation analysis). As a result I have selected variables that are important to the quality of team work, and the interactions between them. At the next step I developed the final version of the model, methods for analysing the synergy conditions in teams, presented the program (dedicated application) to search for synergy (based on PCA methods, regression) and built a model of structural equations. From then on, it was possible to indicate selected synergistic variables - i.e. forming synergistic pairs. In other words, to indicate a combination of two variables that reinforce each other, and increase the goal function. In the study, the satisfaction of team work was recognised as the objective function and the qualitative measure of synergy. The significance in the model of synergic variables is related to the fact that they determine the increase in the qualitative measure of synergy. Thus, they can be considered as a manifestation of the occurrence of this phenomenon in a team. The final stage of the research was the initial testing of the research model and the presentation of recommendations for business.

\section{Application of the concept of grounded theory in the study of synergy}

Due to the complex research process and a large amount of collected empirical data, the presentation and discussion of results was divided into stages. To emphasise the validity of the test results of each stage of the process, it was considered appropriate to present them in separate publications. The research objective of this article is to focus attention on discussing the process and results of the first stage - qualitative research. This approach allows maintaining the correct sequence of presenting empirical evidence. The applied case study method enabled to observe an interesting research aspect that focuses on the value and significance of the quality of relations in team working. Then, at the next step, based on qualitative research, I identified hidden, and still sensed by team members, states that enhance the activity of a team. Having diagnosed the environment and its conditions, I applied the grounded theory strategy. The three consecutive actions to recognise the conditions of the synergy are presented graphically in Figure 3.

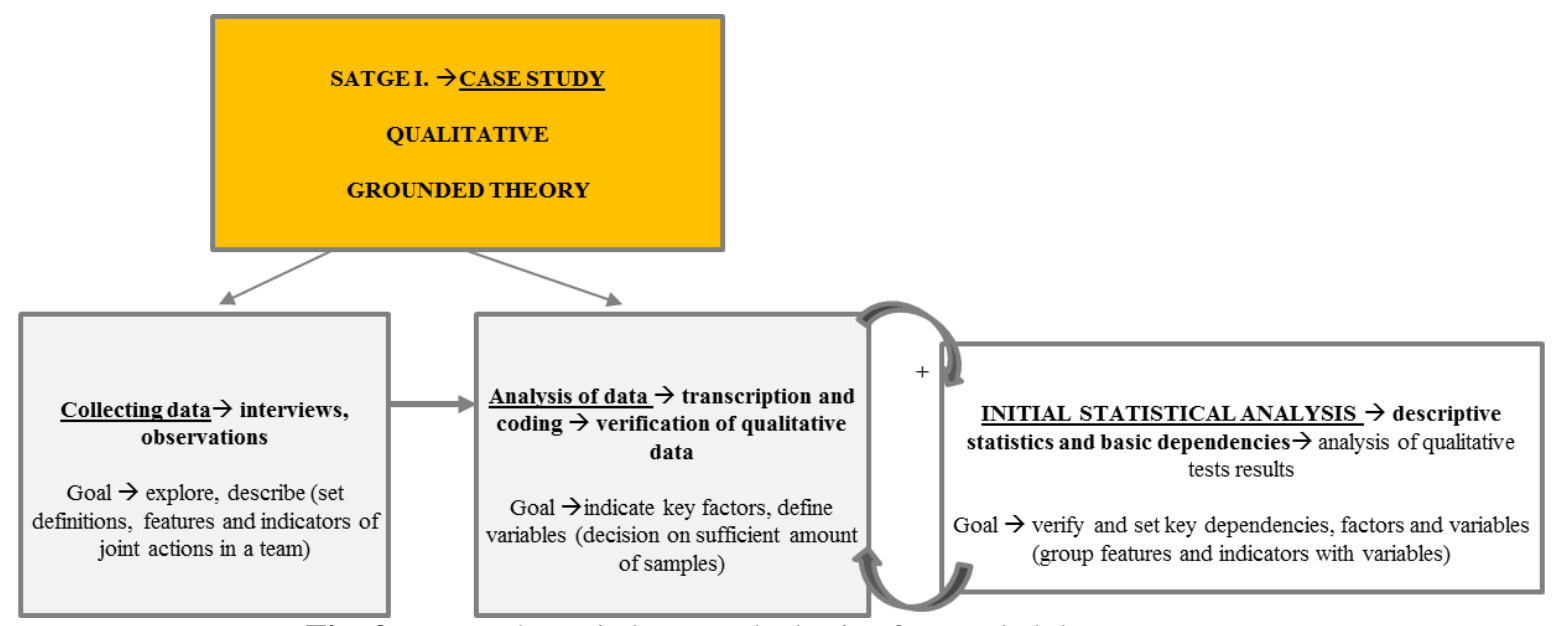

Fig. 3. Research carried out on the basis of grounded theory strategy Source: own study. 


\section{ENTREPRENEURSHIP AND SUSTAINABILITY ISSUES}

ISSN 2345-0282 (online) http://jssidoi.org/jesi/

2019 Volume 7 Number 1 (September)

http://doi.org/10.9770/jesi.2019.7.1(27)

The preliminary stage of exploration, the inspiration for the development of the concept of qualitative research was, the analysis of interdisciplinary theoretical research. The accepted analogies, including physics, biology, pharmacology, chemistry, sociology and psychology played a special role in the search's justification and explanation. The second point of reference was the analysis of the empirical data obtained on the basis of reports of applied research projects (the new management system developed in companies based on the results of these studies and proposed solutions) and participant observation. To develop the reports the research process has been carried out in two big companies, which according to basic criteria are considered as developing and managed in an innovative way. The first research area - the "P-M" company takes into account the competences of personnel within the integrated management system. In the second area - the "S" company, I studies attitudes and opinions on the introduced changes and ways to build relations in an organisation. Two different research projects, implemented in two companies from different industries stressed one common and yet important aspect. It was the quality of the team work and the factors that underlie it. The author of this article was both the manager and contractor of the research. Works under applied research projects were completed about six months before the start of the qualitative research phase. This time allowed for respective conclusions, consultations with both scientific representatives and managerial personnel and subsequent development of a new concept. In addition to acquiring new knowledge about the behaviour of people in modern organisations, I primarily focused on introducing solutions in practice. This was another opportunity to collect information on the application of improvement proposals, determine the response to the change and the effects of this change. The analysed material was obtained by means of the field study method using free interviews, survey and participant observation. Moreover, the statistical analysis of test results has been performed using Pearson's r. With that information (emerging concepts, attributes of empirical material, dependencies) I formed the foundation of problem's pre-conceptualisation (conceptualisation before the study) for further research.

The next step in the research process were initial activities focused on the preparation of qualitative research and verifying companies' possibilities to join the research. This part of the process focused on the reconnaissance, scientific consultations, developing first scenarios of the study, interview and observation cards as well as patterns of code sheets. Determining the initial code key, at this stage, made it possible to prepare the correct procedure for selection and transcription of the empirical material. As a result of the decision to use the case study method and subsequent selection of an apt company for purposes of qualitative research, well-thought preliminary activities were vital. The argument in favour, of "P-M" company for the research project, was the diversity recognised in it. Research-wise, the company was very attractive thanks to the profile of its operations, the size, the area of operations, the complexity of processes and the implementation of quality management assumptions. An important premise as to the choice of the company was the changing management direction, quite a number of the changes and dynamics used to carry them out, and above all, the multiplicity of the teams within the company.

The preliminary stage was also related to the selection of the sample for qualitative research. The choice was deliberate and based on the criteria of rational selection of the subject. The research unit comprised teams which met the size and type prerequisite. Due to the properties selected for the study, prior the quota sampling, an earlier determination of the characteristics of the teams in the organisation has been performed. Having gathered relevant information on the basis of the lists prepared by the managerial personnel and HR departments, 22 teams were selected for the study. Employees and leaders from seven teams attended in-depth (a total of 59 people). Generally, this part of the study includes project teams. The rest i.e. 15 teams took part in group interviews (141 people in total). The research included also senior management but not as part of teams but as individuals managing the teams (14 people). Taking into account the size criterion, there were five teams in the group interview: i) small up to 6 people, ii) medium 7-11 people, iii) large ones over 11 people. While selecting the research teams I kept the type ratio, which gave three teams of each type: i) managerial, project (task), ii) operational, iii) trouble-shooting, and iv) advisory. The total duration of the preliminary work was 4 months. 


\section{ENTREPRENEURSHIP AND SUSTAINABILITY ISSUES}

ISSN 2345-0282 (online) http://jssidoi.org/jesi/ 2019 Volume 7 Number 1 (September) http://doi.org/10.9770/jesi.2019.7.1(27)

The case study based concept implemented in "P-M"company included two ways of research. The first concerned the qualitative study stage based on the grounded theory. The results of this study will be presented and discussed later in the article. The second step in this area is the preliminary survey. This activity was a transition to the fundamental stage of the study - quantitative research. The survey has been carried out on 22 teams and it was the starting point for the verification of the constructed set of integrated tools. The questionnaires, surveys and the preliminary assessment of the acquired material were used for discussions with the managerial personnel and for scientific consultations (this part of the research results will be presented in another article).

In the context of the above-mentioned proceedings, with the empirical reference I initiated the process of identifying the theory, which has been done on the basis of systematically collected and continuously analysed data (Konecki K.T., 2009), all according to the principle of the grounded theory. In this way, I used exploration and description to implement the first stage - the qualitative research using grounded theory strategy. The concepts, phenomena, and behaviours discovered and defined at that stage derive from the description of the observed and surveyed group of employees. It was one of the most important steps that made it possible to determine the scope of terminology and the conceptual meaning of the main variables. And at the second stage of the study, I also determined variable indicators and their features, which after apt verification were applied.

As a result, the first part of the grounded strategy yielded qualitative data in the form of 64 interviews. Their types and timeframes are presented in Table 1. The interviews were recorded by means of: a digital recorder (a dictaphone) and in the form of notes / flashcards, in line with the prepared question scheme. The method of recording depended on the conditions in the company and the attitude of the team. The openness of the teams to the digital recording of the study was more pronounced in the case of group interviews (focus group). Participants of individual interviews more often preferred a written record. The premise of such decisions was the need to build a greater sense of security and freedom when answering questions. Then, the empirical material was transcribed. According to the developed formula, the answers were transferred to the code sheet. Moreover, I tagged the validity and frequency of the answers, as well as any emerging doubts. Furthermore, during the interviews I managed to specify comprehensibly any areas that are difficult to investigate. As a result, main categories of variables have been selected and described. The analysis and grouping of features characterising the sources, course and effects of team work enhanced the research even more.

Table 1. Types and time of interviews in qualitative research - the context of grounded theory

\begin{tabular}{|c|c|c|}
\hline Interview & $\begin{array}{l}\text { Number of } \\
\text { participants }\end{array}$ & Timeframe \\
\hline $\begin{array}{l}\text { 1. Individual in-depth interview with members of the } \\
\text { team (IDI - individual in-depth interview) }\end{array}$ & 45 people & $60-75$ minutes \\
\hline $\begin{array}{l}\text { 2. Individual interview with team management and team } \\
\text { leaders (IDI - individual in-depth interview) }\end{array}$ & $\begin{array}{c}28 \text { people } \\
\text { (including } 14 \\
\text { people in teams) }\end{array}$ & $60-90$ minutes \\
\hline 3. Different types of teams (FGI - Focus group interview) & $\begin{array}{c}15 \text { teams } \\
\text { (141 people in all) }\end{array}$ & 80 - 120 minutes \\
\hline
\end{tabular}

Source: own study.

In-depth individual interviews were conducted with team members as well as managerial personnel and team leaders. The collected data allowed to indicate the behaviours and determinants of these behaviours. This proved to be important from the point of assessment of the quality of the team's operation and team work. In turn, 


\section{ENTREPRENEURSHIP AND SUSTAINABILITY ISSUES}

ISSN 2345-0282 (online) http://jssidoi.org/jesi/ 2019 Volume 7 Number 1 (September) http://doi.org/10.9770/jesi.2019.7.1(27)

interviews with the managerial personnel and team leaders were the basis for obtaining objective verification of the effectiveness of team work. Subsequently, I performed a description of the characteristics of the team, which turns out to be significant to organisation of work and functioning of a team. In addition, I pointed to the context of the organisational conditions which are crucial for effective performance of team efforts. A total of 103.5 hours was devoted to interviews, with an active participation of 214 people. Individual stages of qualitative research, such as: scenario development, data collection, transcription, exploration, were conducted over a period of nine months (taking into account the break due to changes in the company). The duration of this stage included not only the acquisition of data, but also the entire sequence of mutually complementing activities. In accordance with the principle of grounded theory (Konecki K.T., 2011), theoretical sampling was a complex and controlled process carried out in order to generate theory. These activities were carried out according to a specific pattern: [test preparation (1) - data collection (1) - verification and coding (1) - material analysis (1) - description of results (1) and decision on further actions] $\rightarrow$ [test preparation (n) - data collection (n) - verification and coding (n) material analysis (n) - description of results (n) and decision on further actions]. The theory that emerged in the process, was the decisive factor as to direction, procedure, number of samples and groups to be compared. The constantly appearing similar examples constituted a theoretical saturation and effected in stopping the sampling process (Charmaz K., 2014). On this basis, I commenced formulating categories and describing their features. That procedure, also reinforced the empirical conviction that the derived theory should be considered as a derivative of empirical data analysis.

Interviews were carried out in a specific order, as indicated in Table 1. It was a sequence of coherent research, which enabled to surface, one by one, definitions and concepts that explained the conditions governing team's efficient operations. The first sequence was the individual interviews with team members. After collecting and developing the material, it was analysed and this was the staring point and a direction to proceed with respect to the issues raised during individual interviews with the managerial personnel and team leaders. At this stage, I observed new threads that described the effects of the teams' functioning, so again the data underwent thorough development and verification. With the two types of interviews, the research portrayed a more accurate picture of the potentially conducive to synergy conditions in a team. The summary of the results of the survey, which was carried out on the basis of individual interviews, was a turning point in qualitative research.

The defined basic concepts, new definitions, presented key conditions and defined specific effects of the quality of team work were the foundation of the third type of interview - focus group. Moderated group interviews aimed at verifying the material obtained so far, focusing on the efficiency of team working. The intention was also to start a discussion on the essence and value of synergy in teams and modern organisations. Before the third type of interviews, but after scientific consultations, I established the scope and developed scenario of the research. The course of group interviews was often dynamic but also inspiring in the context of emerging new issues. They most often pointed to the role and importance of a team as an intelligent collective as well as to the inventiveness in a team working.

The participant observation complemented the conducted focus interviews. It registered general behaviours and team reactions, especially during discussions. It seemed important to describe the forces that increase the effectiveness of joint actions. Thus empirically I saw that a team is able to produce better quality, higher value solutions than the sum of the individual actions. Not only the scope of the problem of the study and its result referred to the conditions under which the phenomenon of synergy may occur, the very course of the study, especially in the context of five teams, provided important explanations of how works a high efficiency team. It was observed what could happen between team members (in terms of emotional, cognitive and behavioural aspects) at the moment when the team begins to perceive and understand the value of the effects achieved in the team work. It was valuable to see the mutual influence of the team members. Amazingly, I also captured the awareness building process of a team, which members encourage each other when generating solutions. I also 
noticed how a group of cooperating individuals can use this emerging higher quality of relations in pursuit of common goals and development.

The characteristics features of teams and their members are crucial for any interpretation and understanding of further research hence I decided to include that data here. Analysis of this material will allow you to pay attention to potential dependencies and attempt to identify and explain the basis for creating the quality of team work. Table 2 presents the main features of teams and their participants obtained during interviews.

Table 2. Features of teams and members based on the qualitative research

\begin{tabular}{|c|c|c|c|c|c|c|c|c|c|}
\hline \multirow[t]{2}{*}{ Interview } & \multirow[t]{2}{*}{ Size } & \multirow[t]{2}{*}{ Type } & \multicolumn{2}{|c|}{ Gender } & \multicolumn{5}{|c|}{ Age } \\
\hline & & & $\mathbf{F}$ & $\mathbf{M}$ & $>\mathbf{3 0}$ & $30-39$ & $40-49$ & $50-59$ & $\leq \mathbf{6 0}$ \\
\hline \multirow{7}{*}{ Individual } & Big & Project & 7 & 5 & - & 4 & 6 & 2 & - \\
\hline & Smal & Project & 3 & 3 & - & 2 & 3 & - & 1 \\
\hline & Big & Project & 8 & 4 & - & 6 & 5 & 1 & - \\
\hline & Small & Project & 6 & - & - & - & 5 & 1 & - \\
\hline & Medium & Project & 2 & 5 & - & 1 & 5 & 1 & - \\
\hline & Medium & Project & 5 & 3 & - & 4 & 3 & 1 & - \\
\hline & Medium & Project & 4 & 4 & 1 & 4 & 2 & 1 & - \\
\hline \multirow{15}{*}{ Focus group } & Medium & Project & 7 & 2 & 2 & 4 & 3 & - & - \\
\hline & Big & Project & 9 & 6 & 2 & 5 & 5 & 3 & - \\
\hline & Small & Managerial & 3 & 3 & - & 3 & 2 & 1 & - \\
\hline & Big & Operational & 11 & 6 & - & 9 & 5 & 3 & - \\
\hline & Medium & Operational & 3 & 5 & - & 5 & - & 2 & 1 \\
\hline & Big & Advisory & 6 & 8 & 1 & 2 & 7 & 3 & 1 \\
\hline & Small & Trouble-shooting & 3 & 2 & - & - & 3 & 2 & - \\
\hline & Small & Operational & 2 & 3 & - & 2 & 2 & - & 1 \\
\hline & Big & Managerial & 10 & 8 & - & 9 & 3 & 4 & 2 \\
\hline & Small & Project & 2 & 3 & - & 2 & 3 & - & - \\
\hline & Medium & Trouble-shooting & 3 & 4 & - & 3 & 4 & - & - \\
\hline & Medium & Managerial & 4 & 3 & - & 3 & 4 & - & - \\
\hline & Big & Trouble-shooting & 7 & 5 & 2 & 6 & 4 & - & - \\
\hline & Small & Advisory & 3 & 3 & - & 3 & 3 & - & - \\
\hline & Medium & Advisory & 4 & 3 & - & 3 & 2 & 2 & - \\
\hline
\end{tabular}

Source: own study. 


\section{ENTREPRENEURSHIP AND SUSTAINABILITY ISSUES}

ISSN 2345-0282 (online) http://jssidoi.org/jesi/

2019 Volume 7 Number 1 (September)

http://doi.org/10.9770/jesi.2019.7.1(27)

The presented team features, defining size and type, were the result of deliberate selection. The features identifying team members, however, allow to notice differences in terms of gender and age. Men were more likely to participate in the study (56\%) than women (44\%). Considering the age of the respondents, they were usually in the middle age range 30-49 (about 80\%). The smallest age groups of respondents participating in the interviews was the youngest group, i.e. below 30 years-old (4\%) and the oldest, i.e. over 60 years-old (3\%). The features of the teams and their members taken into consideration above, as research results show, are important for building the quality of relationships and their activity. Moreover, data obtained in accordance with the principle of the grounded theory, also indicate other features important from the point of view of the conditions of synergy. They will be discussed in the context of the research results presented below.

\section{Presentation and discussion of research results - preliminary research stage}

Discussion of the research results in this part will be consistent with the first stage of the project presented in Figure 2. The focus will be on the presentation of empirical evidence in relation to the first and second step of qualitative research. The analysis will take into account the reports developed as part of the applied research carried out and interviews and observations carried out in accordance with the principle of grounded theory.

The starting point for the presentation of the main results of the research is to refer to the sources of inspiration of the developed concept of studying synergy conditions in teams for that reason, I applied our research projects in two large enterprises. The "PM" and "S" companies differ in terms of organisation and management type. The obtained results designed new or crucial upgrades to the existing management systems and the developed conclusions created the basis for the perception of a new value and a targeted use of the potential of the organisation, taking into account, in particular, the human factor in the team work. The information of the study can be considered as an element of an emerging concept that has been established in the field (organisation).

The first reference point for the developed study concept are reports of tests carried out in the "P-M" company, prepared on the basis of 484 questionnaires. They concerned the verification of personnel competences in the scope of functioning of the integrated management system. At present, companies consider competences as significant capital, which are valued intangible assets. In this sense, competences are a set of conscious, put-inpractice attitudes, knowledge and skills that are significant for both operational and strategic activities that support the development of modern organisations. They create the potential of the organisation, which stands for the company's competing ability by means of quality of products and services offered. A competence is a proof of effective performance. This is the ability to use the knowledge and skills to achieve the company's objectives. It is also important to express positive attitudes, especially in relation to the development of entrepreneurial activity, commitment, satisfaction, creativity or adaptation.

Three dimensions of competences were taken into account in the study and assessment: knowledge (W) - skills (U) - attitudes (P), in relation to employees and managerial personnel. Fig. 4 presents the main elements of competence in the aspect of obtained values and established dependencies occurring between them. The average assessment of individual elements was based on aggregated indicators, which were measured using a five-point Likert scale, where 1 is the lowest and 5 the highest value.

Knowledge is an indispensable element of building awareness of action. Its scope and level is the basis for the efficiency of the tasks, setting and achieving new goals and making good decisions. Understanding the need to improve knowledge is a significant element in shaping the attitudes of staff, which in turn enhances efficiency. Knowledge has been defined by 25 features indicating its proficiency level, ability to apply in practice, and specifying the sources of its acquisition. In the research I have also assessed the influence of knowledge on other areas and entities performing joint actions. 
Skills have been treated as a necessary factor to ensure apt quality of the tasks. The use of skills in the assigned work requires appropriate knowledge. If it is submitted for productive use while reinforcing skills, it will contribute to the effectiveness of the actions taken. Skills can be considered as employees' abilities that allow you to perform well-defined activities and create new solutions. The element (skills) has been described by means of 10 features that identify proficiency level, the ability to use in practice, the improvement of processes and undertaken actions. On top of that I studied and assessed skills in the context of their development and improvement.

The third component of competence - attitudes has been described by means of 12 features. Attitudes are expressed in behaviours, in the manner of undertaken actions and in the expressed relation to the entire organisation. Any organisation must develop and implement specific mechanisms, i.e. creating an appropriate working environment, proper influence on personnel conduct, and building a pro-active organisational culture when shaping attitudes. Positive attitudes are important for achieving tangible results and raising the quality level of the tasks performed. This is especially evident if I consider the commitment or staff satisfaction. Active attitudes are a reinforcement for developing and applying knowledge and improving skills. The analysis included the attitude towards assigned duties and expectation regarding support provided to perform the work. In terms of the performance I have also decided to assess the involvement and satisfaction from work, plus I paid attention to the ability to see the benefits of team work, the need for improvement and the possibility of increasing our efficiency.

On the basis of statistical analysis, I defined the relationship between competency components (K-S-A), I used Pearson's R with the significance level of these dependencies expressed as $p<0.001$. And the reliability of questionnaire (78 questions) has been measured by the Cronbach Alpha coefficient ( $\boldsymbol{\alpha})$. The internal coherence of the tool was considered high $\rightarrow \alpha=0.865$.

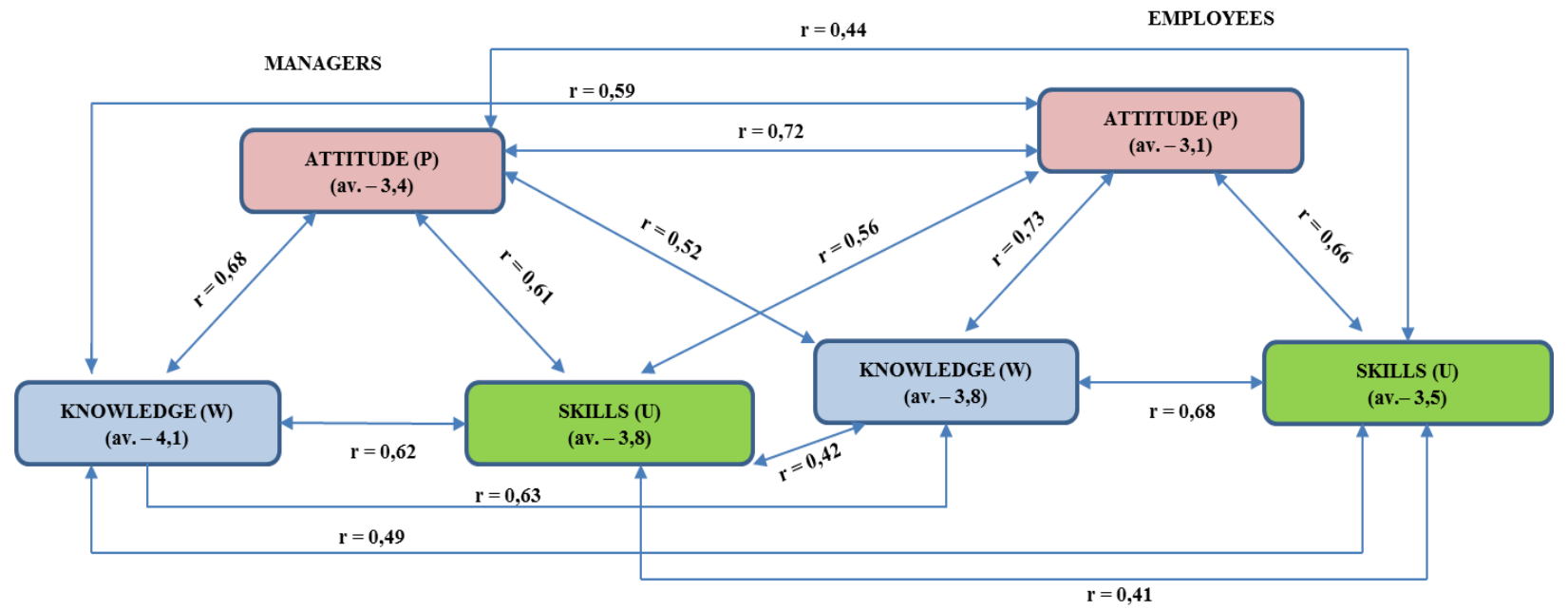

Fig. 4. Evaluation and dependence of attitudes towards changes and opinions towards relationships in the company Source: own study.

The results of the survey indicate that in three dimensions (K-S-A) the level of staff competences is higher for managers (average score 3.8) than for employees (average score 3.5). There is some similarity in the assessments that occur between the two groups. The obtained results are distributed in a similar way, but the average values of these assessments are lower by 0.3 points at employees. The element of knowledge is the highest in both groups. 


\section{ENTREPRENEURSHIP AND SUSTAINABILITY ISSUES}

ISSN 2345-0282 (online) http://jssidoi.org/jesi/ 2019 Volume 7 Number 1 (September) http://doi.org/10.9770/jesi.2019.7.1(27)

In this respect, management obtains a higher rating (4.1) compared to employees (3.8). Skills come second, in terms of the ratings obtained. In the case of the managerial staff (3.8), this level is higher than for employees (3.5). However, the poorest link in the competences of both groups are attitudes. Their level can generally be estimated as only sufficient. In the managerial staff, attitudes rated (3.4) are slightly higher than in employees (3.1), which may result from a higher level of knowledge and awareness of responsibility for actions in the organisation.

As shown by the dependencies presented (Figure 4), the strongest relations occur in the internal set of competence elements (K-S-A) of individual groups of respondents. In both cases, these are positive and high correlations. The relationship between variables in the K-S-A system is significant, which may indicate a strong mutual influence of these factors in team work. A special role in this system is played by attitudes that despite the relatively low average grades show the strongest relations, especially in relation to knowledge $(r=0.73, r=0.68, r=0.59)$ and the attitudes of others $(r=072)$. This may mean that knowledge increases the individual's awareness, which in turn shapes attitudes. On this basis, one can speak about the operation of two strong groups of factors that enable a change in attitudes. It is about the scope and quality of knowledge that builds awareness of action, mutual learning, imitation of attitudes and cognitive openness.

A high correlation also occurs between the knowledge of the managerial staff and employees' knowledge $(\mathrm{r}=$ 0.63). This significant dependence indicates the important role of knowledge in the process of organisational and collective learning. Efficient communication and high quality of relations would enhance the process. This only supports the idea that the flow of knowledge in an organisation requires cooperation and the creation of an appropriate networking to create a new quality and innovative knowledge.

Knowledge and skills presented also significant dependence. A higher correlation in this system takes place in the case of employees $(r=0.68)$ than in the management $(r=0.62)$. Well-used skills require the knowledge. Knowledge supports efficiency, directs actions, facilitates the performance of duties. Awareness of their potential creates a basis for understanding phenomena and processes taking place in the organisation and its environment. This circumstance increases the possibility of fuller use, but also improvement of skills during joint work. Attitudes also strengthen possessed skills and that indicate a significant dependence, both in employees $(r=0.66)$ and in management $(\mathrm{r}=0.61)$. This element of competence is important from the point of view of activity and involvement in action. Properly shaped attitudes, allow you to achieve more, faster and better while team working.

The second inspiration for the developed concept of the study is a report on the research carried out in the "S" company, based on 290 employee surveys. The aim of the project was to study attitudes and opinions on the introduced changes and the way of building relations in the company. The changes in contemporary organisations have a more dynamic character, their number increases, but the time needed to implement them is shortened. Increasingly, they require the use of comprehensive solutions and undertaking entrepreneurial activities. The change process should focus not only on building efficiency, but first and foremost on the development of the organisation. It requires conscious and active cooperation. Teamwork, knowledge, attitudes and social relations play an important role in making changes. The value of human and social capital in the change process, is of strategic importance and a foundation of future organisation.

The research referred to five main areas describing the employees' attitude to the implemented changes and the assessment of relations created in that situation. Figure 5 shows assessments and dependencies. The first dimension of the study was the opinion of the staff on their participation in the process of changes and the development of the company. The second aspect took into account the awareness of the benefits and threats resulting from the introduced changes. The third part of the study included the opinions and assessment of the staff on communication between colleagues. The fourth scope of the study was to get an opinion on the relations 
between employees and the company. The fifth empirical dimension concerned the staff opinion on behaviour towards work.

Each of the presented five dimensions has been treated as an aggregated indicator, described by 12 to 15 features. The variables were measured by using a five-point Likert scale, where 1 was the lowest and 5 the highest value. In addition, a statistical analysis was carried out between the variables based on Pearson's $r$ ratio. The study used relations at the significance level of $\mathrm{p}<0.001$. The reliability of the questionnaire was also evaluated (73 questions in total) using the Cronbach alpha ratio $(\boldsymbol{\alpha})$. The results show a very high internal cohesion of the tool at the level of $\alpha=0.898$.

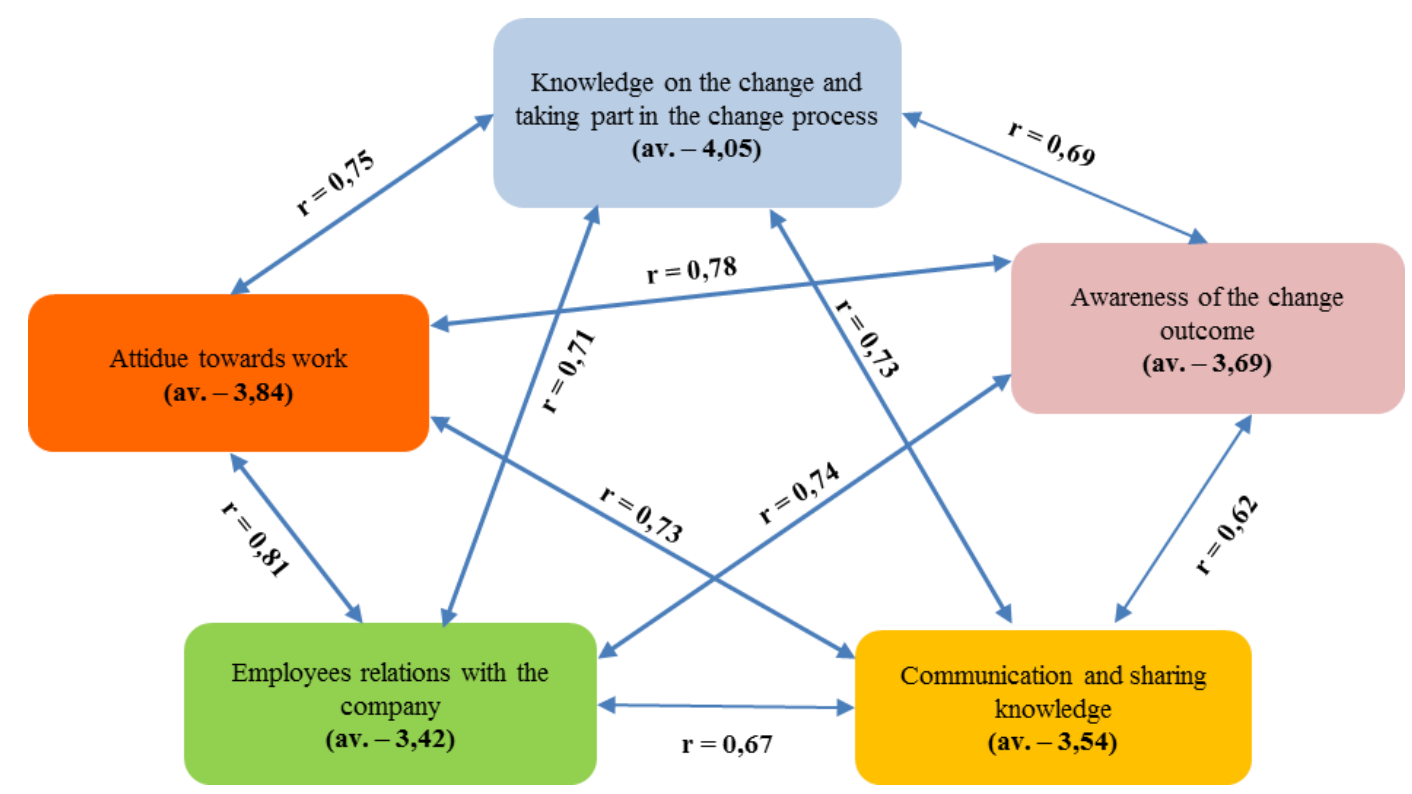

Fig. 5. Evaluation and dependence of attitudes towards changes and opinions towards relations in the company Source: own study.

On the basis of the analysis of the survey results, it can be generally stated that the value of the average employees' assessment of changes, their course and the relations in the company created in those circumstances indicates quite well result of (3.71). The highest ratings (4.05) within the five verified areas, has the knowledge about changes and employee participation in the process. This may indicate the appropriate awareness of personnel in which direction the changes go and the willingness to actively participate at the stage of their planning and implementation. The personnel's behaviour towards work is quite well (3.84). It can be assumed, in this case, that there are well-established behaviours, although this may not always result from the actions of the managerial staff (e.g. commitment, satisfaction). It should also be assumed that support is needed to maintain and develop behavioural activities, especially those that are important for the quality of team work (including trust, kindness, mutual assistance). The study presented that the awareness of the effects of changes (3.69), communication and knowledge sharing (3.54) and employee relations with the company (3.42) are below the average. On this basis, it can be preliminarily assumed that social capital should be developed especially in the change process, the attitudes of openness to team work should be strengthened and the knowledge management mechanism in the organisation should be improved.

The statistical elaboration of the research results enabled the identification of significant relations (Figure 5) between the five discussed dimensions. One very large relation was observed in the variable system $(\mathrm{r}=0.81)$. It points out that the relations between employees and the company are strongly related to behaviour towards work. 


\section{ENTREPRENEURSHIP AND SUSTAINABILITY ISSUES}

ISSN 2345-0282 (online) http://jssidoi.org/jesi/

2019 Volume 7 Number 1 (September)

http://doi.org/10.9770/jesi.2019.7.1(27)

On this basis, it can be assumed that properly shaped and strengthened behaviour towards work will translate into the quality of the employee's relations with the company.

An element of behaviour that strengthens the relations between employees and the company is generally a good assessment of employees own competences. It is created on the basis of a high level of awareness of the professional role, high level of competence in relation to tasks and experience at work. This approach is related to the quite high level of education and seniority in the company. The element that is weaker in the assessment is support for the development of competences and the average assessment of competencies of employees. This

result has its grounds in the quality of relationships with colleagues and management, which require significant enhancement. The result may be a lack of openness and trust in the team work. This will slow down the entrepreneurship and effectiveness of personnel in achieving goals.

In general, it means that there is a good overall level of knowledge of employees in relation to the work performed and a fairly well-developed range of professional skills. However, what raises doubts is the average degree of using knowledge and skills in the undertaken work. In this case, one can point again to the argument of the average quality of relationships and the use of limited forms of activity in the tasks performed. This maintains the view that employees do not use their potential fully. Probably this is due to inadequately arranged cooperation and low level of challenges at work. These are important arguments, mainly in the aspect of building a sense of meaning and value in teamwork.

Considering involvement and identification as a sign of building relations with the company, a quite good level of behaviour in work organisation and a good assessment of the effects of cooperation plays an important role. The weakness observed at behaviour analysis is the low level of quality of relations, especially between departments in the company. This has its effect in poor coordination of joint activities and inefficient communication. The cooperation in teams or organisational units is quite good, but it is weak in the relations between teams / organisational units. Such situation, resulting form deficits of behaviour, causes significant threats in communication, and in the flow of information and sharing knowledge $(r=0.73)$. It also limits the awareness of the achieved effects in the organisation and creates conditions for the occurrence of negative attitudes. This situation disturbs the implementation of processes, creates a low level of social capital and, as a result, slows down the development of the organisation.

The weakest link of behaviour towards work is the attitude of personnel. They were defined by such indicators as: commitment to work, job satisfaction, trust towards colleagues, focus on cooperation and care for the quality of cooperation, kindness, help in team work. The behaviour towards work, allows to point to high correlations with the awareness of changes effects (benefits and threats) and joint work $(\mathrm{r}=0.78)$. It can be assumed that if employees' awareness on the consequences of changes for the organisation and for themselves, is increased, they will be more likely to show more positive attitudes. It concerns both the proactive approach, including the attitude towards entrepreneurship, creativity, innovation and cognitive and social openness.

A high correlation $(r=0.75)$ also occurs between knowledge about changes and participation of employees in the change process and behaviour towards work. The rationale for this dependence is the significant impact of employee involvement in planning and implementation of changes and information on the benefits of changes to attitudes, knowledge and skills. This is in line with the theory that the success of changes depends on the appropriate preparation of people for this process and enabling them to create the change. This approach generates operational efficiency, appropriate use of potential and creates added value. In addition, positive and active attitudes reduce or eliminate resistance to change and change load. 


\section{ENTREPRENEURSHIP AND SUSTAINABILITY ISSUES}

ISSN 2345-0282 (online) http://jssidoi.org/jesi/ 2019 Volume 7 Number 1 (September) http://doi.org/10.9770/jesi.2019.7.1(27)

Another high correlation $(\mathrm{r}=0.74)$, perceived in the study, is the relation between the employees' relations with the company and the awareness of the effects of changes. This situation suggests that if employees have knowledge of real or potential benefits and risks, they will be more open to what is happening in the organisation. Thus employees identify more with the company and get involved in its operations. This applies mainly to entrepreneurial activity and suggesting new directions of development in the organisation. Building and maintaining an appropriate level of trust and quality of relations in the team work can only strengthen the dependence.

It can be assumed that, the variable partially mediating between building a relation with the company and the awareness of the effects is an adequate level of knowledge about changes and the attitude of employees towards change. The confirmation of this is the significant dependence $(\mathrm{r}=0.71)$ on the relation between employees and the company - knowledge about changes and participation in the change process e.g. providing good flow of information and the right sources, and making employees aware of what is going on in the organisation will make them more involved in the company's affairs and open to joint activities. In addition, the possibility of participation will create a good ground for shaping trust and bearing responsibility for the quality of the relationship. In this respect, it is worth noting the next significant dependence i.e. knowledge about changes and the awareness of their effects $(r=0.69)$. It means that participation and sharing knowledge develops the ability of employees to perceive and understand the benefits and threats resulting from the process of change in the organisation.

In view of knowledge management as the most important management system in learning organisations I go to the next high correlations. The study included two dimensions of the system, which is the communication subsystem and knowledge sharing. In this respect, reference should be made to two significant relations. First dependence $(r=0.73)$ related to employees' knowledge of changes and their involvement in the change process. An appropriate communication system, defined by good flow and sources of information, effective communication between the managerial staff and employees, is the basis for creating knowledge resources in the organisation. It also enables the efficiency of knowledge generation, localisation and transfer processes. The high quality of relations $(r=0.67)$ is a reinforcement of this dependence system, which justifies the importance of participation in building engagement, openness to cooperation and identification with the company. In this context, attention is also drawn to positive attitudes, especially towards team work. Empirical evidence $(r=0.73)$ justifying this view is the significant relation between communication and knowledge sharing with behaviour towards work, which is indicated by attitudes (kindness, mutual help, content). In addition, adequate cognitive openness, trust and commitment to collaborative work not only increase the ability to share knowledge, but most of all they create it. As a result, a new value of knowledge in the organisation is created that increases the scope, quantity and quality, which are important in the context of shaping innovative and creative behaviours.

\section{Presentation and discussion of research results in the view of grounded theory}

The first part of the analysis of research results presented above gave rise to some key findings. The main one, indicates a certain feature that occurs in the state of high activity of team work. It was estimated that there is some strength in the actions of people that can generate an outstanding effect. This is particularly evident when people start cooperating with each other in an appropriate manner. It has become an inspiration for consolidating the need for new exploration of and for defining and describing the phenomenon. Another finding draws attention to the significant role of the quality of relations in achieving the efficiency of work. It was also noticed that team work increases the openness to sharing employees' potential and the appropriate use of their knowledge and skills. It was established that the cooperation, reinforced by the awareness of human resources, is an indispensable element for the process of mutual learning and development in the organisation. 


\section{ENTREPRENEURSHIP AND SUSTAINABILITY ISSUES}

ISSN 2345-0282 (online) http://jssidoi.org/jesi/ 2019 Volume 7 Number 1 (September) http://doi.org/10.9770/jesi.2019.7.1(27)

In enhancing team work, the attitudes and behaviours share a paramount importance. It was recognised that appropriate shaping of positive and active attitudes is increasingly becoming a challenge for the managerial personnel in contemporary organisations. In this respect, the managerial personnel must have a sufficient level of numerous competences, including social and personal. The next finding singled out that attitudes are the implication of the quality of the relation, the increase in efficiency of cooperation and the ability to strive for achieving distinctive effects. In the context of shaping attitudes, especially personnel's, it was noticed that it is important to undertake activities that enable them to increase and maintain a high level of job satisfaction and commitment. The opportunity to improve competences and offer an appropriate reinforcement system in this aspect may support this activity.

A great force shaping behaviours, that was discovered in the study, is participation, increasing freedom and awareness in the work of personnel and a sufficiently high level of trust in cooperation. The above findings turn out to be extremely important during changes and setting new directions of development. The study also revealed the value and need to use entrepreneurial activity, creativity and the possibility to realise the potential in team work. Based on the analysis, it was recognised that the process of organisational learning, based on an efficient system of communicating and sharing knowledge, should be strengthened by the development of social potential in the organisation. Therefore, appropriate shaping of positive attitudes should be considered a valuable investment in social capital.

With such well-established knowledge, further activities related to the development of the concept of a new study were carried out. The main purpose of the undertaken work was to recognise and describe the conditions of the occurrence of the phenomenon, which could be the most indicative of synergy. It was considered that the best way to deal with an unspecified phenomenon would be to apply a grounded theory. The assumption was that the definition and verification of this should be carried out under specific conditions. To this end, a scenario was developed that included a team-oriented study. It was considered that the phenomena that arouse great empirical curiosity will be more clearly observed in a situation when employees consciously interact with one another, observe each other's behaviours and act. The research profile determined in this way assumed the selection of different types of teams. The research unit established the members functioning in specific teams. I assumed the possibility to examine the image of a team that can be considered as a picture of relations, behaviours and effects of team work. Having said that, it means that determining and analysing elements of this image allow us to observe and describe the default feature - confirm the synergy.

In accordance with the accepted strategy of the grounded theory, the first step was to conduct individual interviews with members of selected teams. Initially, the research was simple empirical curiosity, which concerned several main slogans: the quality of relations, team work, the effects of team work, team activity, the activities of the managerial staff, the course of cooperation. The interviewing scenario took into account the possibility of describing the relationship and the way of team's operating. I make sure that respondents could utter their opinions freely but I ensured that out subject to research is completely addressed. At this stage of the study, the word synergy was not used on the part of the interviewer, leaving room for the term to emerge in a natural way.

Based on the established methodology, the collected material was transcribed. Next, the material was verified and further interviews were completed with issues requiring more elucidation or explanation of ambiguity. The first part of the results of qualitative research, obtained on the basis of grounded theory, became a source of basic terms, indicators and features describing the functioning of teams.

The focus group was an extension of individual interviews. It was aimed at verifying and extending the information from previous studies. At this stage of the research, team members were more open to discussion, mutually inspired while responding and looking for justifications. 


\section{ENTREPRENEURSHIP AND SUSTAINABILITY ISSUES}

ISSN 2345-0282 (online) http://jssidoi.org/jesi/ 2019 Volume 7 Number 1 (September) http://doi.org/10.9770/jesi.2019.7.1(27)

I considered it a sufficient amount of knowledge after conducting interviews with members of 22 teams (a total of 200 employees and leaders) including the management of the company (14 people). I have noticed similarities in answers in both forms of the interviews along with the fact that no new information has been brought as a result of further interviews. While elaborating the material, I determined, the most characteristic indicators and features of the team's activities indicated by the respondents. The basic material is presented in Table 3 .

Table 3. Basics of recognising the conditions of synergy in a team based on the principles of grounded theory.

\begin{tabular}{|c|c|}
\hline Question & The most characteristic indicators and features \\
\hline $\begin{array}{l}\text { What is the basis for building and } \\
\text { maintaining the quality of } \\
\text { relationships? }\end{array}$ & $\begin{array}{l}\text { Creating and developing contacts with colleagues: frequency of relations, number of } \\
\text { relationships, relations dynamics, contacts activity, forms of contacts, degree of dependence, } \\
\text { type of interaction, organisation of relationships, closeness of relations, emotions in } \\
\text { relationships, informal relations. } \\
\text { Regulating relationships: relationships, common values, mutual respect and help, interest } \\
\text { in others, adherence to common rules, joint arrangements, common time at work, } \\
\text { responding to difficulties, speaking and explaining. } \\
\text { Communication: forms of communication, transfer of knowledge and information, current } \\
\text { information, timely information, exchange of views, making discussions, language of } \\
\text { communication, openness to others. } \\
\text { Confidence: kindness of colleagues, honesty, sense of justice, sense of security, believe in the } \\
\text { effectiveness of action, trust in competence, believe in opportunities. }\end{array}$ \\
\hline What is important in team work? & $\begin{array}{l}\text { Team's potential: commitment to team work, tenacity in pursuing goals, focus on } \\
\text { organisation and task, responsible conduct, openness to initiative, openness to change. } \\
\text { Work organisation: awareness of the course of action, setting common goal, foster work } \\
\text { and relation, freedom of action, work overload and time pressure, time for team work, } \\
\text { awareness of dependence. } \\
\text { Competences: knowledge and skills (appropriate resources, sharing knowledge, developing } \\
\text { knowledge, improving skills), attitudes (commitment, giving something from each other, role } \\
\text { awareness, content, identification). }\end{array}$ \\
\hline What is the effect of joint actions? & $\begin{array}{l}\text { Activity in a team work: sharing knowledge, learning in a team, searching for solutions } \\
\text { together, innovation, openness to development, willingness to take risks, perceiving new } \\
\text { opportunities, innovative behaviours. } \\
\text { Effectiveness: awareness of the effects of work, quality of work, efficiency, effort at work, } \\
\text { elimination of errors in work, effectiveness of team work. } \\
\text { Self-development: openness to development, curiosity in action, development and sharing } \\
\text { of abilities, innovative imagination, non-standard thinking. }\end{array}$ \\
\hline What is the activity in team work? & $\begin{array}{l}\text { Personal activity: motivation to work, innovative attitude, pursuing goals, sharing personal } \\
\text { resources at work. } \\
\text { Team activity: creativity, entrepreneurial action, joint solutions, sensitivity to the } \\
\text { innovations of others, introducing changes, expanding contacts, improving activities, } \\
\text { exchanging experiences. }\end{array}$ \\
\hline $\begin{array}{l}\text { What management activities are } \\
\text { important for building } \\
\text { teamwork? }\end{array}$ & $\begin{array}{l}\text { Motivating: support action, reward extraordinary behaviours, expres appreciation, } \\
\text { recognise the initiative, challenges at work. } \\
\text { Working atmosphere: information flow, feedback, accessibility, information on effects, } \\
\text { promoting activity, supporting innovative behaviours, encouraging team work. }\end{array}$ \\
\hline
\end{tabular}




\section{ENTREPRENEURSHIP AND SUSTAINABILITY ISSUES}

ISSN 2345-0282 (online) http://jssidoi.org/jesi/ 2019 Volume 7 Number 1 (September) http://doi.org/10.9770/jesi.2019.7.1(27)

What to look for in the course of cooperation?
Behaviour at work: mutual inspiration, mutual motivation, focus on team work, sense of community, support of superiors, ability to assemble resources at work.

Difficulties: the ability to control difficult situations, focus on the problem not on the person, independence to overcome difficulties, ability to solve problems.

Source: own study.

In the study, when watching the behaviours, reactions and mutual interaction of respondents I gathered additional information. By the end of every group interview I used the word 'synergy' which evoked multiple reactions from smile, vivid discussion to a prolonged consideration. The respondents, however were inspired by the subject and generally were quite prompt to present their arguments, associations and definitions.

Table 4. The result of synergy exploration and diagnosis in view of grounded theory

\begin{tabular}{|l|l|}
\hline $\begin{array}{l}\text { A new indicator } \\
\text { selected in the survey }\end{array}$ & $\begin{array}{l}\text { Satisfaction: energy to work, sense of common work, value of work, pride of achievement, sense of } \\
\text { development in a team, sense of new opportunities, real impact on cooperation, the effect of } \\
\text { accelerating work, an impression of better quality work. }\end{array}$ \\
\hline $\begin{array}{l}\text { What is the synergy } \\
\text { associated with? }\end{array}$ & $\begin{array}{l}\text { Synergy: pleasure of being in a team, additional contribution to team work, high level of active work, } \\
\text { highly focused, profit, more efficiency, aiming higher, effect of temporary action, team bonus, extras, } \\
\text { doing something more or different, cooperation satisfaction, relation maturity, mutual learning and } \\
\text { development, savings, higher quality, sense of accomplishment and successful team work, sense of } \\
\text { common work, pride of shared achievements, good work, cohesion, internal peace, sense of } \\
\text { community, wisdom of knowledge, willingness to continue cooperation, higher efficiency of operations. }\end{array}$ \\
\hline
\end{tabular}

Source: own study.

With the application of grounded theory to diagnose conditions triggering synergy in teams, I have grouped gathered features in order to analyse them further. Given the division of research areas as presented in tables 3 and 4, I defined seven key dimensions: cooperation, the effect of team work, effort in team work, quality of relations, management (work of managerial personnel), team potential and the indicator discovered in course of the study satisfaction. In the next activity I used the rho-Spearman correlation coefficient to statistically develop qualitative data in the next activity. In this case, for the calculated value of the ' $t$ ' test, the significance is $p<0.001$. The dependence of results is presented in Fig. 6. 


\begin{tabular}{|c|c|c|c|c|c|c|c|}
\hline COOPERATION & - & & & & & & \\
\hline $\begin{array}{l}\text { TEAM WORK } \\
\text { EFFECT }\end{array}$ & $\mathrm{r}_{\mathrm{S}}=\mathbf{0 , 8 4}$ & - & & & & & \\
\hline $\begin{array}{l}\text { EFFORT IN TEAM } \\
\text { WORKING }\end{array}$ & $r_{S}=\mathbf{0 , 4 7}$ & $\mathrm{r}_{\mathrm{S}}=\mathbf{0 , 5 5}$ & - & & & & \\
\hline $\begin{array}{l}\text { QUALITY OF } \\
\text { RELATIONS }\end{array}$ & $r_{S}=0,75$ & $r_{S}=0,66$ & $r_{S}=0,59$ & - & & & \\
\hline SATISFACTION & $r_{S}=0,73$ & $r_{S}=0,79$ & $r_{S}=\mathbf{0 , 5 6}$ & $r_{S}=0,82$ & & & \\
\hline MANAGEMENT & $r_{S}=\mathbf{0 , 6 4}$ & $r_{S}=\mathbf{0 , 6 5}$ & $r_{S}=\mathbf{0 , 5 1}$ & $r_{S}=\mathbf{0 , 6 3}$ & $r_{S}=\mathbf{0 , 6 5}$ & - & \\
\hline \multirow[t]{2}{*}{ TEAM POTENTIAL } & $r_{S}=\mathbf{0 , 5 8}$ & $r_{S}=0,72$ & $r_{S}=0,46$ & $r_{S}=0,62$ & $r_{S}=0,61$ & $r_{S}=\mathbf{0 , 4 5}$ & - \\
\hline & COOPERATION & $\begin{array}{c}\text { TEAM WORK } \\
\text { EFFECT }\end{array}$ & $\begin{array}{c}\text { EFFORT IN } \\
\text { TEAM WORKING }\end{array}$ & $\begin{array}{l}\text { QUALITY OF } \\
\text { RELATIONS }\end{array}$ & SATISFACTION & MANAGEMENT & $\begin{array}{c}\text { TEAM } \\
\text { POTENTIAL }\end{array}$ \\
\hline
\end{tabular}

Fig. 6. The result of the rho-Spearman correlation coefficient of the main variables of the quality of team work Source: own study.

Taking into account the overall correlation result, it can be stated that volume of dependencies appearing in the presented system is somewhat substantial. This only supports the mutual influence of the examined variables as significant in the indication of synergy in teams. Figure 6, clearly points out two very high correlations. The first shows a very large dependence $\left(r_{S}=0.84\right)$ between cooperation and the effect of team work. It means that the quality of cooperation translates into measurable effects of the team. The behaviour at work, which increases the activity and effectiveness of team work, is particularly important. Another very high correlation $\left(r_{S}=0.82\right)$ is the relation between satisfaction and the quality of the relation. Here, the quality of relations in team work defined by the level of trust and the quality of contacts between colleagues creates conditions in which team members can experience the pleasure of working together. In addition, efficient communication, knowledge sharing and relation building creates a sense of development, new opportunities and increases the real impact on cooperation.

A high correlation $\left(r_{S}=0.79\right)$ that occurs between satisfaction and the effects of team work is another argument defining favourable conditions for synergy. This relation reinforces the view that a state of pleasure in team work can be achieved if its effects meet or exceed the expectations of team members. In the context of the effects of team work, reference should also be made to significant dependence $\left(\mathrm{r}_{\mathrm{S}}=0.72\right)$ with the potential of a team. Commitment to team work, perseverance in pursuing goals and focus on action convert to effectiveness and quality in achieving results by the team. This dependence is legitimated by the influence of self-development of team members on their cognitive openness, entrepreneurial initiative and willingness to make changes. In view of the above, synergy seem to manifest itself as the energy created by satisfaction enhanced by the high quality of relations in team, the effects of team work and the possibility of realising and developing their own potential when working together.

Moreover, the analysis draws attention to the significant relationship $\left(r_{s}=0.75\right)$ established between the quality of relations and cooperation. In this respect, mutual inspiration, mutual reinforcement and a sense of community in developing relations and building trust are important. What should be stressed in this relationship is the importance of the quality of communication and the regulation of relations (norms, rules) in difficult situations in the team. The ability to master difficulties and the ability to solve problems require mutual trust and faith in the effectiveness of action. From the point of view of the quality of the relation, the effect of team work is significant 


\section{ENTREPRENEURSHIP AND SUSTAINABILITY ISSUES}

ISSN 2345-0282 (online) http://jssidoi.org/jesi/

2019 Volume 7 Number 1 (September)

http://doi.org/10.9770/jesi.2019.7.1(27)

in dependence $\left(\mathrm{r}_{\mathrm{S}}=0.66\right)$. It is the quality of contacts that conditions activity in a team work. Sharing knowledge, mutual learning, joint search for solutions will be possible if the team provide appropriate frequency, number and form of contacts. Let's not forget that the type of interaction can increase openness to development.

Cooperation and satisfaction presented high correlation $\left(r_{S}=0.73\right)$. Thus it should be assumed that properly arranged cooperation, while maintaining high quality relation, will increase the satisfaction of team members. Particularly, the support of superiors and the ability to assemble the necessary resources at work can create a sense of encouragement and a real impact on cooperation. In this approach, the autonomy in overcoming difficulties may bring the sense of awakening new opportunities and development. Another collaboration significant variable $\left(r_{S}=0.58\right)$ is the team's potential. This is where the relation between commitment to work and responsible conduct and a sense of community in a team should be indicated. The positive relation between openness to change and autonomy in overcoming difficulties also support that significant correlation.

The statistical data allowed to see the validity of management (managerial staff) in creating conditions for synergy. In this context, a fairly high correlation can be indicated in relation to building cooperation $\left(r_{S}=0.64\right)$, effects of team work $\left(r_{S}=0.65\right)$, shaping the quality of relations $\left(r_{S}=0.63\right)$ and building satisfaction in a team $\left(r_{S}=\right.$ 0.65). The role of the managerial staff in this area is to create and apply appropriate mechanisms to strengthen knowledge, skills and attitudes. The challenge for managers is to shape and utilise potentials, build good environment for team work, support activity and innovation in the organisation.

An interesting finding is a moderate correlation of effort in team work in relation with: cooperation $\left(\mathrm{r}_{\mathrm{s}}=0.47\right)$, the potential of team $\left(r_{S}=0.46\right)$, management $\left(r_{S}=0.51\right)$, satisfaction $\left(r_{S}=0.56\right)$, and the quality of the relation $\left(r_{s}=0.59\right)$. It can be assumed that there are some hidden or unacknowledged factors in this study that may have a greater impact on the team working effort. There may well be a lot of such factors that is why the analysis indicated a significant but moderate relation. In the context of the indicators, the most important for the effort are difficult situations and ability to deal with problems, organisation of and focus on work, time management and sense of common work, and let's not forget the impact of team work support and promoting, support for activity and freedom of work. However, the most important element for the effort in the team work is the quality of the relation in a team. In this respect, one should refer to the flow of knowledge, sharing experience, the type and number of contacts, as well as kindness and trust in the competences of colleagues.

The intention to implement the study based on the grounded theory strategy was the opportunity to recognise and describe preliminary conditions supporting synergy in a team. Based on the results and subsequent analysis, it should be assumed that the goal has been achieved. The study was complex and demanding, both at the stage of acquiring and developing data. Nevertheless, with great satisfaction I can point that the research consolidated satisfaction the knowledge about synergy in practice.

\section{Conclusions}

Initially, the first stage of research allowed to identify conditions of synergy and to indicate key features for the quality of team work. In course of the research I developed of an integrated set of research tools to collect and later to develop and analyse data. One of the tools was a questionnaire to analyse joint activities in a team, the next was a questionnaire describing the functioning of a team and a company. Both surveys are a complementary set of information that will allow subjective and objective evaluation of team work.

The validity of qualitative research shows that the synergy in a team may emerge from the opportunity to notice new aspects. The first stage of the research, recognised the potential and natural conditions supporting and 


\section{ENTREPRENEURSHIP AND SUSTAINABILITY ISSUES}

ISSN 2345-0282 (online) http://jssidoi.org/jesi/ 2019 Volume 7 Number 1 (September) http://doi.org/10.9770/jesi.2019.7.1(27)

creating teamwork's quality. The study identified the dependencies between the team's effectiveness and organisational premises and established the scope of understanding the concept and effects of synergy. Furthermore, in course if the research I managed to identify the essence of the relation between the synergy and the quality of relations and the shaping of social capital in the team. All that work was a foundation to build the appropriate language code, important in the development of surveys and questionnaires and subsequent sheet codes in the database during the second and third stage of the study.

The role of active teams is to create learning organisations, stimulate development and spring them to a higher level - innovation. To achieve all that a company must set the direction of innovative work and master teamworking. A success in this means creative, new and unique ideas, which value come from both novelty and usability (Perry-Smith J.E., Shalley C.E., 2003). In an intensively competitive and dynamic environment, innovations become the most important factor influencing the organisation's success (Udwadia F.U., 1990).

\section{References}

Albors-Garrigos, J., Ramos-Carrasco, J.C., Peiro-Signes, A. 2016. Actional Intelligence, a Key Element for Actioning Knowledge. A Field Study Analysis. Journal of Information \& Knowledge Management 15(1) https://doi.org/10.1142/S0219649216500064

Amabile, T.M., Kramer, S.J. 2011. The power of small wins. Harvard Business Review 89(5): 70-80. https://hbr.org/2011/05/the-power-of$\underline{\text { small-wins }}$

Amabile, T.M. 1988. A model of organizational innovation. In BM Staw, LL Cummings (Eds.) Research in organizational behavior. 10: $123-167$.

Atkočiūnienė, Z., Girnienè, I. 2015. Impact of Knowledge Management Processes on the Creation of Innovations: Case Study. Proceedings of the 16th European Conference on Knowledge Management/Academic Conferences and Publishing International Limited. 2015, p. 321329. http://toc.proceedings.com/27956webtoc.pdf

Černevičiūtè, J., Strazdas R. 2018. Teamwork management in Creative industries: factors influencing productivity. Entrepreneurship and Sustainability Issues 6(2): 503-516. http://doi.org/10.9770/jesi.2018.6.2(3)

Chang, S.C., Lee, M.S. 2008. The linkage between knowledge accumulation capability and organizational innovation. Journal of Knowledge Management 12 (1): 3-20. https://doi.org/10.1108/13673270810852359

Chang, S.C., Lee, M.S. 2007. A study on relationship among leadership, organizational culture, the operation of learning organization and employees' job satisfaction. The Learning Organization 14(2): 155-185. https://doi.org/10.1108/09696470710727014

Charmaz, K. 2014. Grounded Theory in Global Perspective: Reviews by International Researchers. http://citeseerx.ist.psu.edu/viewdoc/download?doi=10.1.1.858.8343\&rep=rep1\&type=pdf

Coleman, J.C. 1988. Organizations and Institutions: Sociological and Economic Approaches to the Analysis of Social Structure. American Journal of Sociology 94:95-S120.

https://faculty.washington.edu/matsueda/courses/587/readings/Coleman\%201988.pdf

Corning, P.A. 1995. Synergy and self-organization in the evolution of complex systems. Systems Research. 12(2) https://doi.org/10.1002/sres.3850120204

Curşeu, P.L., Meslec, N., Pluut, H., Lucas, G.J.M. 2015. Cognitive synergy in groups and group-to-individual transfer of decision-making competencies https://www.frontiersin.org/articles/10.3389/fpsyg.2015.01375/full

Erdem, M., İlğan, A., Uçar, H.I. 2014. Relationship between Learning Organization and Job Satisfaction of Primary School Teachers.

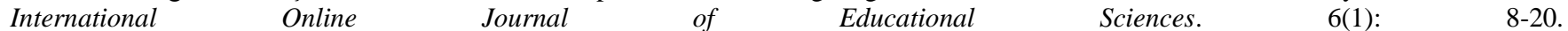
http://citeseerx.ist.psu.edu/viewdoc/download?doi=10.1.1.658.1690\&rep=rep1\&type=pdf 


\section{ENTREPRENEURSHIP AND SUSTAINABILITY ISSUES}

ISSN 2345-0282 (online) http://jssidoi.org/jesi/ 2019 Volume 7 Number 1 (September) http://doi.org/10.9770/jesi.2019.7.1(27)

Giedraitis, A., Stašys, R., Skirpstaite, R. 2017. Development possibilities of the management team within a production company. Entrepreneurship and Sustainability Issues, 5(2), 212-222. http://doi.org/10.9770/jesi.2017.5.2(4)

Jasińska, M. 2015. Synergy, the result of intelligent cooperation. http://www.irdo.si/skupni-cd/cdji/cd-irdo-2015/referati/15-monikajasinska-paper.pdf

Konecki, K.T. 2011. Visual Grounded Theory: A Methodological Outline and Examples from Empirical Work, 131-160. https://www.researchgate.net/publication/233991214_Visual_Grounded_Theory_A_Methodological_Outline_and_Examples_from_Empiri cal_Work

Konecki, K.T. 2009. Teaching Visual Grounded Theory. Qalitative Sociology Review 5(3). https://www.researchgate.net/publication/233991153_Teaching_Visual_Grounded_Theory;

https://hrcak.srce.hr/file/106256

Lawford, G.R. 2003. Beyond success: Achieving synergy in teamwork. Journal for Quality and Participation 26(3): 23-27. http://asq.org/qic/display-item/index.html?item=19781

Logan, L.R. 1995. A natural synergy. Team Performance Management. An International Journal 1(1): 12-17. https://doi.org/10.1108/13527599510064922

Perry-Smith, J.E., Shalley, C.E. 2003. The social side of creativity: A static and dynamic social network perspective. Academy of Management Review 28: 89-106. http://dx.doi.org/10.2307/30040691

Putnam, R.D. (ed.). 2004. Democracies in Flux: The Evolution of Social Capital in Contemporary Society. Oxford University Press, New York, 345p.

Rabey, G. 2003. The paradox of teamwork. Industrial and Commercial Training 35(4): 158-162. https://doi.org/10.1108/00197850310479141

Senge, P.M. 2010. The fifth discipline: The art and practice of the learning organization. Crown Publishing Group. New York, 168p.

Senge, P.M. 2014. The fifth discipline fieldbook: Strategies and tools for building a learning organization. Crown Business, New York, $356 \mathrm{p}$.

Senge, P., Kleiner, A., Roberts, Ch., Ross, R., Roth, G., Smith, B., Guman, E.C. 2007. The dance of change: The challenges to sustaining momentum in learning organizations. https://solonline.org/wp-content/uploads/2016/12/Study-Notes-for-the-Dance-of-Change.pdf

Senge, P., Kleiner, A., Roberts, C., Ross, R., Roth, G., Smith, B. 1999. A Fifth Discipline: The Dance of Change: The Challenges of Sustaining Momentum in Learning Organizations. Crown Business. New York, 345p.

Slávik, Š., Hagarová, R., Ljudvigová, I., Zagoršek, B. 2019. Business model and team as preconditions of a start-up viability.

Entrepreneurship and Sustainability Issues 6(3), 1204-1227. http://doi.org/10.9770/jesi.2019.6.3(25)

Udwadia, F.U. 1990. Creativity and innovation in organizations: Two models and managerial implications. Technological Forecasting and Social Change 38(1): 65-80. https://doi.org/10.1016/0040-1625(90)90018-Q

Zeeman, A. 2017. Senge's Five Disciplines of Learning Organizations. https://www.toolshero.com/management/five-disciplines-learningorganizations/

\section{Acknowledgements}

The paper has been prepared on the basis of a fundamental research project - Synergy and Social Capital of Modern Organisations. The project was financed by the National Science Centre with funds allocated on the basis of decision-DCE 2011/01/BHS4/04810. 


\section{ENTREPRENEURSHIP AND SUSTAINABILITY ISSUES}

ISSN 2345-0282 (online) http://jssidoi.org/jesi/

2019 Volume 7 Number 1 (September)

http://doi.org/10.9770/jesi.2019.7.1(27)

Monika JASIŃSKA is $\mathrm{PhD}$ in politics, specialist in management and public administration. Currently, she works in the Department of Organisation and Management of the Faculty of Economics and Legal Sciences of Siedlce University of Natural Sciences and Humanities. She is a member of the Advisory Council of the Polish Agency for Enterprise Development Research Centre. She is focuses on developing synergy in teams, researching learning organisations, growing social and human capital in organisations. She studies the development of entrepreneurship and innovation and building active conduct in organisations. At present her work deals with synergy in modern organisations. Her researches include innovation aspects, effective team working and knowledge management. She manages research projects, which are often conducted in cooperation with the industry to get the ultimate result i.e. improvement of organisation management.

ORCID ID: orcid.org/0000-0001-9231-4469

Register for an ORCID ID:

https://orcid.org/register

Copyright (C) 2019 by author(s) and VsI Entrepreneurship and Sustainability Center

This work is licensed under the Creative Commons Attribution International License (CC BY).

http://creativecommons.org/licenses/by/4.0/

cC) (i) Open Access 